ASTHMA

\title{
Relationship between exposure to domestic allergens and bronchial hyperresponsiveness in non-sensitised, atopic asthmatic subjects
}

\author{
S J Langley, S Goldthorpe, M Craven, A Woodcock, A Custovic
}

Thorax 2005;60:17-21. doi: 10.1136/thx.2004.027839

See end of article for authors' affiliations .....................

Correspondence to: Dr S J Langley, Medicines Evaluation Unit, North West Lung Centre, Wythenshawe Hospital Manchester M23 9LT, UK; slangley@meu.org.uk

Received 6 May 2004 Accepted

9 September 2004

\begin{abstract}
Background: The effect of exposure to allergens not causing sensitisation in atopic asthmatic subjects has not previously been studied. A study was undertaken to assess the degree of asthma severity (measured by spirometry, airway reactivity and exhaled nitric oxide) in atopic asthmatic patients not sensitised to the domestic allergen to which they were exposed.

Methods: Dust samples were collected from the living room carpet and mattress in the homes of 248 subjects and dust mite, cat and dog allergen concentrations were measured. Spirometry, non-specific bronchial reactivity (BR), and exhaled nitric oxide (eNO) were ascertained. Patients' sensitisation status was assessed by skin prick testing.

Results: Adult atopic asthmatics not sensitised to mite but exposed to high levels of mite allergen had significantly more severe $B R$ than subjects not exposed to high levels of mite $\left(\mathrm{PD}_{20}\right.$, geometric mean (GM) $0.21 \mathrm{mg}(95 \% \mathrm{Cl} 0.09$ to 0.47$)$ v $0.86 \mathrm{mg}(95 \% \mathrm{Cl} 0.44$ to 1.67$)$, mean ratio difference 4.1 (95\% Cl 1.5 to 11.4), $p=0.008$ ). Subjects not sensitised but exposed to high levels of dog allergen also had significantly more severe $B R$ than subjects not exposed $\left(P_{20} G M 0.16 \vee 0.52 \mathrm{mg}\right.$, mean ratio difference $3.3(95 \% \mathrm{Cl} 1.2$ to 9.2$), p=0.01)$. The differences in BR between these groups were still significant after adjusting for confounding factors. This effect of greater airway reactivity was not seen in subjects exposed but not sensitised to cat allergens.

Conclusion: Atopic asthmatic subjects who are exposed to high levels of dust mite or dog allergens but not sensitised to these allergens have evidence of increased airway reactivity.
\end{abstract}

$\mathrm{T}$ he inhalation of allergens in atopic asthmatic subjects in clinical studies is associated with bronchoconstriction. Subjects who have a late asthmatic response to allergen also show an exaggerated response to non-specific bronchoconstrictor agents (such as histamine or methacholine). This occurs after both high dose and repeated low dose allergen challenge. ${ }^{2}$ An increase in non-specific airway reactivity also occurs after natural exposure to perennial ${ }^{3}$ and seasonal ${ }^{4}$ allergens, and the heightened airway responsiveness can occur without significant bronchoconstriction. ${ }^{2}$

Most observational and experimental research has focused on the effect of allergen exposure in subjects who are sensitised to that specific allergen. However, it is possible that increased airway responsiveness upon allergen exposure may in part be due to factors other than the generation of an allergic reaction-for example, some allergens are proteolytic enzymes $^{5}$ that cleave epithelial tight junctions ${ }^{6}$ which may lead to increased permeability of the airways.

This study forms part of an ongoing project in which we have previously demonstrated the relationships between different physiological measures of asthma severity ${ }^{7}$ and also assessed the effect of exposure to sensitising allergens in allergic subjects. ${ }^{8}$ We have shown in these two studies that bronchial reactivity appeared to be more severe in atopic asthmatic subjects than in non-atopic asthmatic subjects and that exposure to allergens to which a subject is also sensitised is related to a more severe bronchial reactivity. We now report on the relationship between the natural exposure to domestic allergens and lung function, airway responsiveness, and exhaled nitric oxide in atopic asthmatic subjects who were not sensitised to the allergen to which they were exposed. Our null hypothesis was that exposure to allergen which is not causing sensitisation does not affect the objective measures of asthma severity.

\section{METHODS}

Subjects were recruited from the North West Lung Centre Medicines Evaluation Unit clinical trials database and outpatient clinics if the following criteria were met: physician diagnosed asthma; asthma symptoms in the previous 12 months; no exacerbation in the previous 4 weeks; sensitised to one or more common inhalant allergens (dust mite, dog and/or cat).

Subjects gave written informed consent following a full explanation of the study. The study protocol was approved by the local research ethics committee.

\section{Study procedures}

Subjects underwent the following procedures having avoided their asthma medication as follows: short acting $\beta$ agonists (6 hours); long acting $\beta$ agonists, leukotriene antagonists and theophyllines (at least 12 hours).

Measurement of exhaled nitric oxide (eNO) eNO was measured before spirometry and bronchial challenge using a chemiluminescence analyser (LR 2000; Logan Research, Rochester, UK). Subjects inhaled fully to total lung capacity and then exhaled slowly (at a controlled rate of $6 \mathrm{l} / \mathrm{min}$ ) to residual volume into a wide bore Teflon tube with minimal resistance. The response time (10-90\%) was $<0.6$ seconds and the sampling rate was $250 \mathrm{ml} / \mathrm{min}$. The

Abbreviations: $\mathrm{BR}$, bronchial reactivity; eNO, exhaled nitric oxide; $\mathrm{FEV}_{1}$, forced expiratory volume in 1 second; FVC, forced vital capacity 
nitric oxide reading was taken when the level had reached a plateau and the carbon dioxide concentration exceeded 5\%. The mean of two readings was taken.

\section{Lung function testing}

Forced expiratory volume in 1 second $\left(\mathrm{FEV}_{1}\right)$ and forced vital capacity (FVC) were measured using a Microlab 3000 spirometer (MicroMedical, Rochester, UK). The best of three technically acceptable efforts was recorded.

\section{Assessment of airway reactivity}

Bronchial challenge was performed if the subject's $\mathrm{FEV}_{1}$ was $\geqslant 60 \%$ of the predicted value. A modified Yan technique bronchial challenge ${ }^{9}$ was used to obtain a cumulative provocative dose of either histamine or methacholine causing a fall in $\mathrm{FEV}_{1}$ of $20 \%$ or more $\left(\mathrm{PD}_{20} \mathrm{FEV}_{1}\right)$. For technical and supply reasons, either histamine or methacholine was used for the provocation solution and the first and last concentrations differed slightly (histamine $3.13 \mathrm{mg} / \mathrm{ml}$ to $50 \mathrm{mg} / \mathrm{ml}$, methacholine $1.56 \mathrm{mg} / \mathrm{ml}$ to $50 \mathrm{mg} / \mathrm{ml}$ ). As previous studies $^{1011}$ have shown that the two compounds produce similar results, dose equivalence was presumed for our study.

A Koko DigiDoser dosimeter (PDS Research, Louisville, CO, USA) and "646" nebuliser pots (Devilbiss, Somerset, PA, USA) were used for the challenge. Cumulative doubling doses of the provocation solution were given immediately after each measurement of lung function which was performed 1 minute after the dose of histamine/methacholine. The challenge was terminated when a fall in $\mathrm{FEV}_{1}$ of $20 \%$ or greater was reached. The $\mathrm{PD}_{20} \mathrm{FEV}_{1}$ was calculated (using cumulative doses) from the following formula: $\mathrm{PD}_{20}=\operatorname{antilog}[\log \mathrm{D} 1+(\log \mathrm{D} 2-\log \mathrm{D} 1)(20-\mathrm{R} 1) /(\mathrm{R} 2-$ $\mathrm{R} 1)]$. The equation is derived from linear interpolation. In subjects who did not demonstrate a $20 \%$ fall in $\mathrm{FEV}_{1}$ following the challenge, a $\mathrm{PD}_{20}$ of $12 \mathrm{mg}$ was entered as the result (one "doubling dose" above the final cumulative dose).

\section{Skin prick testing}

Skin testing was performed by the prick method (Dermatophagoides pteronyssinus, cat and dog, negative and positive controls; Bayer, Elkhart, IN, USA). Sensitisation was defined as a wheal diameter at least $3 \mathrm{~mm}$ greater than the negative control.

\section{Home visits and assessment of allergen exposure}

Dust samples were collected by vacuuming a $1 \mathrm{~m}^{2}$ area of living room carpet and mattress for 2 minutes. Dust extracts were assayed for content of $\operatorname{Der} p \mathrm{l}, \mathrm{Fel} d \mathrm{l}$, and $\operatorname{Can} f \mathrm{l}$ using monoclonal antibody based enzyme linked immunosorbent assays as previously described. ${ }^{12-14}$ The results were expressed as $\mu \mathrm{g}$ allergen/g fine dust.

\section{Statistical analysis}

The statistical analysis was performed using SPSS 10.1 for Windows (SPSS, Chicago, IL, USA). The conventional 5\% level of statistical significance was used. Results of $\mathrm{PD}_{20}$, eNO, and allergen concentrations were log transformed and are reported as geometric means (GM) with 95\% confidence intervals (CI). Independent sample $t$ tests were used for the comparative analysis of lung function data between any two groups.

A univariate analysis of variance was used to assess for any imbalance between the exposed/non-exposed groups due to confounding factors. The factors analysed were sex, age, smoking status, number of years with the diagnosis of asthma, use of inhaled steroids, dose of inhaled steroids if used, and the geometric mean levels of the other two confounding allergens (in carpet and mattress) in each group
Table 1 Demographic details of study subjects $(n=248)$

\begin{tabular}{|c|c|}
\hline \multicolumn{2}{|l|}{ Characteristic } \\
\hline Mean (range) age (years) & $41(11-68)$ \\
\hline $\operatorname{Sex}(M / F)$ & $105(42 \%) / 143(58 \%)$ \\
\hline \multicolumn{2}{|l|}{ Smoking status, n (\%) } \\
\hline Smokers & 33 (13\%) \\
\hline Non-smokers & $215(87 \%)$ \\
\hline \multicolumn{2}{|l|}{ Asthma treatment } \\
\hline Receiving inhaled steroids, n (\%) & $149(60 \%)$ \\
\hline Mean, median (range) & $658 \mu \mathrm{g}, 400 \mu \mathrm{g}(100-2000)$ \\
\hline Not receiving inhaled steroids, $n(\%)$ & $99(40 \%)$ \\
\hline Mean (range) $\mathrm{FEV}_{1} \%$ predicted & $87.4 \%(24-132)$ \\
\hline \multicolumn{2}{|l|}{ Allergen sensitisation ( $\mathrm{n}(\%)$ positive): } \\
\hline Dust mite & 185 (75\%) \\
\hline Cat & $149(60 \%)$ \\
\hline Dog & $124(50 \%)$ \\
\hline \multicolumn{2}{|l|}{ Allergen exposure (to high levels): } \\
\hline Dust mite & $109(46 \%)$ \\
\hline Cat & $63(25 \%)$ \\
\hline Dog & $52(22 \%)$ \\
\hline
\end{tabular}

(for example, the levels of dog and cat allergens in the group of subjects not sensitised to house dust mite). A potential confounding factor was included in the multivariate analysis if it had a $\mathrm{p}$ value of $\leqslant 0.1$. Analyses of $\mathrm{PD}_{20}, \mathrm{FEV}_{1}$ and eNO were adjusted for, using this same model, if confounding factors were found between the different groups.

To assess for bias between subjects receiving methacholine and histamine in the bronchial challenges, interaction between the method and any association was tested in a multivariate analysis.

Some subjects in our study did not undergo a bronchial challenge test, mostly because their lung function precluded the test while some refused the investigation. Technical problems prevented measurements of eNO in some subjects. However, post hoc power calculations showed that the study has approximately $80 \%$ power to detect differences of two doubling dilutions between groups for $\mathrm{PD}_{20}$ (assuming a standard deviation of 0.7 for the $\log _{10}$ values), $6.5 \mathrm{ppb}$ between groups for eNO (assuming a standard deviation of 0.36 for the $\log _{10}$ values), and $13 \%$ between groups for $\mathrm{FEV}_{1}$ $\%$ predicted (assuming a standard deviation of 18 ).

\section{RESULTS}

Two hundred and forty eight subjects were recruited into the study (table 1). Dust mite was the most common allergen causing sensitisation $(\mathrm{n}=185$ subjects). Subjects were classified as being exposed to high levels of domestic allergens based on previously proposed criteria if the allergen levels were $>2 \mu \mathrm{g} / \mathrm{g} \operatorname{Der} p \mathrm{l},>10 \mu \mathrm{g} / \mathrm{g}$ Fel $d \mathrm{l}$, and $>10 \mu \mathrm{g} / \mathrm{g}$ Can $f 1$ in either site (carpet or mattress). ${ }^{15}{ }^{16}$ Dust mite was also the most common allergen to which subjects were exposed $(46 \%)$.

The distribution of patients in each subgroup is shown in fig 1. Before adjustment for confounding factors, the following results were obtained.

\section{Der $p 1$}

Subjects not sensitised to dust mite had significantly greater airway reactivity (that is, lower $\log \mathrm{PD}_{20}$ ) values when exposed to high levels of $\operatorname{Der} p$ l (table 2). There was a trend towards higher eNO levels in the exposed group but the difference was not statistically significant $(p=0.09)$. There was no difference in $\mathrm{FEV}_{1} \%$ predicted between patients exposed and those not exposed to high levels of Der $p 1$.

\section{Can $f$}

Subjects not sensitised to dogs had significantly greater airway reactivity when exposed to high levels of Can $f \mathrm{l}$ 


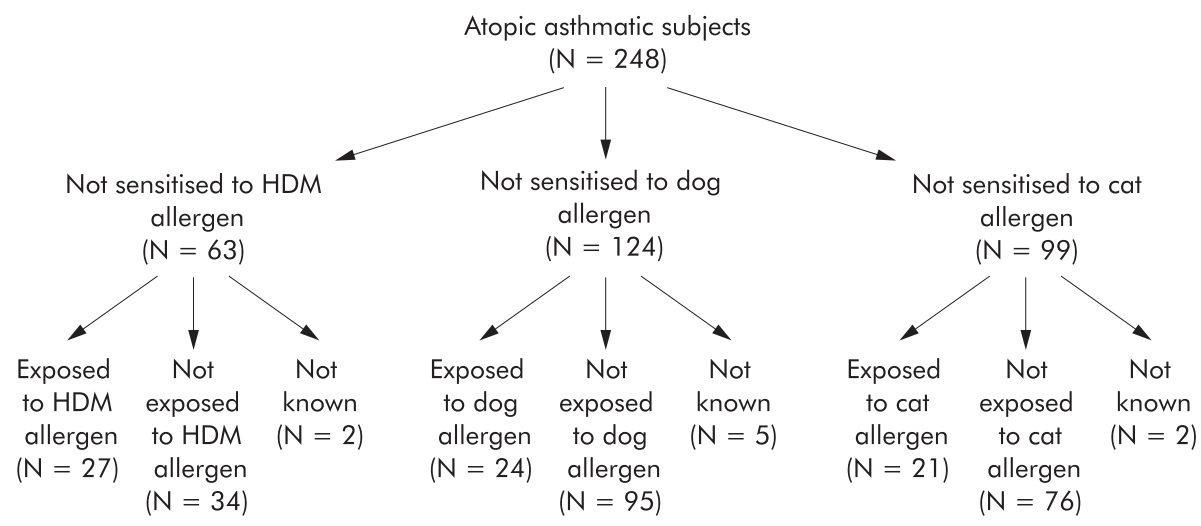

Figure 1 Breakdown of subjects into subgroups (groups are not mutually exclusive).

(table 3), and this group also had significantly higher eNO levels. There was no difference in $\mathrm{FEV}_{1} \%$ predicted between the exposed and non-exposed groups.

\section{Fel $d 1$}

In subjects not sensitised to cat there was no difference in $\mathrm{PD}_{20}$, eNO, or $\mathrm{FEV}_{1} \%$ predicted between those exposed to high levels of that allergen and those not exposed.

Univariate analysis showed that, of the confounding factors considered (sex, age, smoking status, number of years with the diagnosis of asthma, use of inhaled steroids, dose of inhaled steroids if used, and the geometric mean levels of the other two allergens), only age was a significant associate for $\mathrm{PD}_{20}$, and only in the non-dog sensitised group. Age, inhaled steroid dose, and smoking status were significant associates for eNO. After adjusting for these, the difference in eNO levels between the Der $p$ l exposed and non-exposed groups in the non-house dust mite sensitised subjects and also the Can $f \mathrm{l}$ exposed and non-exposed subjects in the non-dog sensitised subjects failed to reach significance $(p=0.07$ and $p=0.08$, respectively).

If the diagnosis of sensitisation was re-defined as a wheal diameter of $2 \mathrm{~mm}$, bronchial reactivity was still greater in subjects not sensitised but exposed to mite $(p=0.03)$ and also subjects not sensitised but exposed to dog allergens $(p=0.01)$. As the number of subjects was fairly small, a formal dose-response effect of allergen was not performed, but a modest but significant $(R=-0.4, \mathrm{p}=0.009)$ correlation was seen between bronchial reactivity and $\log \operatorname{Der} p 1$ level in the mattresses of subjects not sensitised to mite. $\chi^{2}$ tests showed no significant difference between the actual and expected frequency of exposure to high levels of confounding allergens for subjects not sensitised to dust mite-that is, in non-house dust mite sensitised subjects there was no difference in the frequency of high $\operatorname{Can} f \mathrm{l}$ or $\mathrm{Fel} d \mathrm{l}$ exposure in the two groups (exposed or not exposed to $\operatorname{Der} p$ 1). The same applied with the non-dog sensitised subjects-that is, there was no difference in the incidence of high Der $p$ l or Feld $l$ exposure in the two groups (exposed or not exposed to Can $f$ 1 allergen). In the analysis of potential confounding allergens between the groups, the only significant finding was that subjects not sensitised to dust mite who were exposed to high levels of that allergen had a significantly higher level of Can $f$ 1 allergen in their mattress than subjects who were not exposed to Der $p 1$ allergen (GM $1.45 \mu \mathrm{g} / \mathrm{g}$ (95\% CI 0.52 to $4.07) v 0.41 \mu \mathrm{g} / \mathrm{g}(95 \%$ CI 0.18 to 0.31 ), $\mathrm{p}=0.05$ ). However, after adjusting for the level of Can $f 1$ allergen, there was still a significant difference between the $\operatorname{Der} p$ l exposed and nonexposed groups in terms of their $\mathrm{PD}_{20}$ (GM $0.24 \mathrm{mg}(95 \% \mathrm{CI}$ 0.11 to 0.52$) \vee 0.71 \mathrm{mg}(95 \% \mathrm{CI} 0.37$ to 1.34$), \mathrm{p}=0.04)$.

There was no difference in the expected frequencies of subjects who were sensitised to other domestic allergens which might affect the results-that is, in the non-house dust mite sensitised subjects there was no difference in the expected sensitisation frequency to dog or cat in the $\operatorname{Der} p \mathrm{l}$ exposed/non-exposed groups. This same analysis was performed for the non-dog and non-cat sensitised subjects.

There was no significant difference in bronchial challenge results between subjects receiving histamine ( $48 \%$ of total) and methacholine $\mathrm{PD}_{20}$ (GM $0.29 \mathrm{mg}$ (95\% CI 0.20 to 0.42$) v$ $0.48 \mathrm{mg}$ ( $95 \%$ CI 0.32 to 0.73 ), $\mathrm{p}=0.08$ ). Also, there was no significant difference in the numbers of subjects classified as having normal, mild, moderate, or severe bronchial reactivity between the two groups. The combined analyses adjusted for the method of challenge showed no effect of the method on

\begin{tabular}{|c|c|c|c|}
\hline & & $\begin{array}{l}\text { Exposed to high levels } \\
\text { of Der } p 1\end{array}$ & $\begin{array}{l}\text { Not exposed to high levels } \\
\text { of Der } p 1\end{array}$ \\
\hline $\mathrm{PD}_{20}(\mathrm{mg})$ & $\begin{array}{l}\mathrm{N} \\
\mathrm{GM}(95 \% \mathrm{Cl}) \\
\text { Mean ratio difference }(95 \% \mathrm{Cl})\end{array}$ & $\begin{array}{l}17 \\
0.21(0.09 \text { to } 0.47) \\
4.1(1.5 \text { to } 11.4) \\
p=0.008\end{array}$ & $\begin{array}{l}26 \\
0.86(0.44 \text { to } 1.67)\end{array}$ \\
\hline eNO (ppb) & $\begin{array}{l}\mathrm{N} \\
\mathrm{GM}(95 \% \mathrm{Cl}) \\
\text { Mean ratio difference }(95 \% \mathrm{Cl})\end{array}$ & $\begin{array}{l}25 \\
13.9(9.6 \text { to } 20.1) \\
0.7(0.4 \text { to } 1.1) \\
p=0.09\end{array}$ & $\begin{array}{l}29 \\
9.3(6.8 \text { to } 12.7)\end{array}$ \\
\hline $\begin{array}{l}\mathrm{FEV}_{1} \\
\text { (\% predicted) }\end{array}$ & $\begin{array}{l}\mathrm{N} \\
\text { Mean }(95 \% \mathrm{Cl}) \\
\text { Mean difference }(95 \% \mathrm{Cl})\end{array}$ & $\begin{array}{l}27 \\
87.2 \%(78.8 \text { to } 95.6) \\
7.3(-2.8 \text { to } 17.4) \\
p=0.15\end{array}$ & $\begin{array}{l}33 \\
94.5 \%(88.1 \text { to } 100.9)\end{array}$ \\
\hline
\end{tabular}


Table 3 Pulmonary function data in subjects not sensitised to Can $f 1$ (unadjusted data)

\begin{tabular}{|c|c|c|c|}
\hline & & $\begin{array}{l}\text { Exposed to high levels } \\
\text { of Can } f 1\end{array}$ & $\begin{array}{l}\text { Not exposed to high levels } \\
\text { of Can } f 1\end{array}$ \\
\hline $\mathrm{PD}_{20}(\mathrm{mg})$ & $\begin{array}{l}\mathrm{N} \\
\mathrm{GM}(95 \% \mathrm{Cl}) \\
\text { Mean ratio difference }(95 \% \mathrm{Cl})\end{array}$ & $\begin{array}{l}15 \\
0.16(0.07 \text { to } 0.34) \\
3.3(1.2 \text { to } 9.2) \\
p=0.01\end{array}$ & $\begin{array}{l}67 \\
0.52(0.33 \text { to } 0.82)\end{array}$ \\
\hline eNO (ppb) & $\begin{array}{l}\mathrm{N} \\
\mathrm{GM}(95 \% \mathrm{Cl}) \\
\text { Mean ratio difference }(95 \% \mathrm{Cl})\end{array}$ & $\begin{array}{l}20 \\
14.6(10.5 \text { to } 20.3) \\
1.2(0.43 \text { to } 1.0) \\
p=0.04\end{array}$ & $\begin{array}{l}83 \\
9.8(8.0 \text { to } 12.0)\end{array}$ \\
\hline $\mathrm{FEV}_{1}$ (\% predicted) & $\begin{array}{l}\mathrm{N} \\
\text { Mean }(95 \% \mathrm{Cl}) \\
\text { Mean difference }(95 \% \mathrm{Cl})\end{array}$ & $\begin{array}{l}24 \\
92.0(84.3 \text { to } 99.7) \\
-2.7(-12.4 \text { to } 6.9) \\
p=0.53\end{array}$ & $\begin{array}{l}94 \\
89.3 \text { (84.8 to } 93.8)\end{array}$ \\
\hline
\end{tabular}

the outcomes, and no interaction was seen between the method and any of the exposed/not exposed groups. These data suggest that dose equivalence between the two challenge methods could be assumed.

\section{DISCUSSION}

Our study has shown that airway reactivity was significantly greater in atopic asthmatic subjects who were not sensitised to dust mite or dog when they were exposed to high levels of these allergens. After correcting for potential confounding factors, $\mathrm{FEV}_{1} \%$ predicted and eNO were not significantly affected by exposure to high levels of non-sensitising allergens. This finding which has (to our knowledge) not previously been reported, may have significant implications in the interpretation of the effects of allergens in atopic asthma. The results suggest that exposure to high levels of domestic allergens may be associated with a deleterious effect on atopic asthma, even in subjects who are not sensitised to the specific allergen - that is, the effect is not consequent on the allergen's "allergenicity". A number of factors may have a role in causing this effect.

Several experimental studies have shown that some of the dust mite allergens (for example, Der $p$ 1, 3, 6 and 9) have properties other than their allergenic effects. It has been shown that Der $p \mathrm{l}$ is a cysteine protease digestive enzyme ${ }^{17}$ and $\operatorname{Der} p 9$ is a serine protease that is capable of degrading collagen. $^{18}$ This enzymatic activity might cause airway damage independently from the allergenic effects by breaking down the tight junctions between epithelial cells. This action might cause direct inflammatory damage that could lead to some of the clinical and physiological features of asthma. Herbert et $a l^{19}$ showed that Der $p$ l increases the permeability of bronchial mucosa to albumin, a feature that has been seen in acute asthma exacerbations. ${ }^{20}$ It has also been suggested that Der $p$ l could activate mast cells without IgE involvement, ${ }^{21}$ causing the release of inflammatory mediators. In vitro, Der $p$ l (by virtue of its proteolytic activity) also acts on epithelial cells, triggering a dose related release of the cytokine granulocyte macrophage colonystimulating factor (GM-CSF). ${ }^{22}$ This cytokine prolongs eosinophil survival, further enhancing the inflammatory process. Whether this occurs in vivo is yet to be ascertained. Finally, Der $p$ l may affect mucus secretion in the airway. ${ }^{23}$ In the current study, the fact that increased airway reactivity was not seen in the subjects not sensitised to cat but exposed to high levels of $\mathrm{Fel} d \mathrm{l}$ might be due to the difference in properties of $\mathrm{Fel} d \mathrm{l}$. This allergen does not exhibit the proteolytic activity of some of the D pteronyssinus allergens. These proteolytic enzymes have been found to cleave the tight junctions between cells in the epithelial barrier, potentially allowing the entry of allergens. Fel $d 3$ has been identified as a member of the cysteine protease inhibitor family, ${ }^{24}$ and cysteine proteases have been implicated in enhancing IgE responses. Whether this is the reason for the difference in response between the two allergens is, however, debatable, as Can $f \mathrm{l}$ and 2 may also contain a cysteine protease inhibitor.

As part of the current project involving this same cohort of subjects, we have previously shown that, despite having similar degrees of airway obstruction, atopic and non-atopic asthmatics have differing levels of airway reactivity and eNO. ${ }^{7}$ In addition to the physiological differences, there are also contrasting pathological features. A previous study has shown that there are significant differences in the structure of the airways between atopic and non-atopic individuals. ${ }^{25}$ These include differences in $\mathrm{T}$ lymphocytes and interleukin staining cells but, perhaps more importantly in relation to our study, the degree of epithelial damage was greater in the atopic group, with a negative correlation between epithelial integrity and both the numbers of eosinophils and CD25 positive cells. The authors did not speculate whether any of these features may have been caused by allergens, but it is possible that the differences between the atopic and nonatopic airways might mean that atopic asthmatics are more prone to damage from allergens. It has been proposed that the disruption to the epithelial barrier present in asthmatic airways may allow easier entry to the subepithelial layer (including smooth muscle) for bronchoconstrictor agents and possibly allergens.

In our study we did not measure the level of co-existing endotoxin in the dust samples. It is possible that the presence of endotoxin in the domestic environment may be a confounding factor that could affect asthma activity. For this to be the case, it would be expected that a higher concentration of endotoxin might be found in association with greater levels of domestic allergen exposure. Wickens et $a^{26}$ found a positive association between domestic endotoxin level and a number of factors including the presence of dogs in the house, while Michel et $a l^{27}$ found no correlation between endotoxin and mite allergen concentrations. The effect of endotoxin has been examined in both experimental studies and in the domestic environment. The results of some studies are conflicting. The INGA study ${ }^{28}$ found a positive association between exposure to mite allergens and the symptoms of wheeze and breathlessness, but no association between symptoms and endotoxin exposure. Other research has shown pro-inflammatory effects ${ }^{29}$ and increased bronchial reactivity in non-asthmatic subjects, ${ }^{30}$ as well as heightened reactivity ${ }^{31}$ and increased airway obstruction in asthmatic subjects ${ }^{32}$ after inhalation of endotoxin. Endotoxin may also augment the action of allergens in addition to having its own intrinsic inflammatory actions.

It is possible that a skin prick test threshold of $3 \mathrm{~mm}$ excludes some "sensitised" subjects and that some of the subjects apparently not sensitised to an allergen still have 
enhanced reactivity when exposed to that allergen. However the difference in bronchial reactivity was still present when sensitisation was re-defined as a wheal of $2 \mathrm{~mm}$ diameter or more.

Our results suggest that, within the atopic asthmatic population, exposure to high levels of dust mite and dog allergen is associated with increased airway reactivity even in subjects who are not sensitised to these allergens. Further experimental research may help to elucidate the cause of this phenomenon.

\section{Authors' affiliations}

S J Langley, S Goldthorpe, Medicines Evaluation Unit, Wythenshawe Hospital, Manchester M23 9LT, UK

M Craven, A Woodcock, A Custovic, North West Lung Centre,

Wythenshawe Hospital, Manchester M23 9LT, UK

\section{REFERENCES}

1 Cockcroft DW, Ruffin RE, Dolovich J, et al. Allergen-induced increase in nonallergen bronchial reactivity. Clin Allergy 1977;7:503-13.

2 Sulakvelidze I, Inman MD, Rerecich T, et al. Increases in airway eosinophils and interleukin-5 with minimal bronchoconstriction during repeated low-dose allergen challenge in atopic asthmatics. Eur Respir J 1998;11:821-7.

3 Custovic A, Taggart SCO, Francis HC, et al. Exposure to house dust mite allergens and the clinical activity of asthma. J Allergy Clin Immunol 1996;98:64-72.

4 Robertson DG, Kerigan AT, Hargreave FE, et al. Late asthmatic responses induced by ragweed pollen allergen. J Allergy Clin Immunol 1974;54:244-54.

5 King C, Brennan S, Thompson PJ, et al. Dust mite proteolytic allergens induce cytokine release from cultured airway epithelium. J Immunol 1998;161:3645-51.

6 Wan $\mathrm{H}$, Winton $\mathrm{HL}$, Soeller $\mathrm{C}$, et al. The transmembrane protein occludin of epithelial tight junctions is a functional target for serine peptidases from faecal pellets of Dermatophagoides pteronyssinus. Clin Exp Allergy 2001;31:279-94.

7 Langley SJ, Goldthorpe S, Custovic A, et al. Relationship between pulmonary function, bronchial reactivity and exhaled nitric oxide in a large group of asthmatic subjects. Ann Allergy Asthma Immunol 2003;91:398-404.

8 Langley SJ, Goldthorpe S, Craven M, et al. Exposure and sensitisation to indoor allergens: association with lung function, bronchial reactivity and exhaled nitric oxide in asthma. J Allergy Clin Immunol 2003;1 12:362-8.

9 Yan K, Salome C, Woolcock AJ. Rapid method for measurement of bronchial responsiveness. Thorax 1983;38:760-5.

10 Juniper EF, Frith PA, Dunnett $C$, et al. Reproducibility and comparison of responses to inhaled histamine and methacholine. Thorax 1978;33:705-10.

11 Salome CM, Schoeffel RE, Woolcock AJ. Comparison of bronchial reactivity to histamine and methacholine in asthmatics. Clin Allergy 1980;10:541-6.

12 Luczynska CM, Arruda LK, Platts-Mills TAE, et al. A two-site monoclonal antibody ELISA for the quantitation of the major Dermatophagoides spp. allergens Der $\mathrm{p} 1$ and Der f 1. J Immunol Methods 1989; 1 18:227-35.
13 Chapman MD Aalberse RC, Brown MJ, et al. Monoclonal antibodies to the major feline allergen Fel d 1: Il. Single step affinity purification of Fel d 1, Nterminal sequence analysis and development of a two site immunoassay to assess Fel d 1 exposure. J Immunol 1988;140:812-8.

14 Schou C, Hansen GN, Lintner T, et al. Assay for the major dog allergen Can f 1: investigation of house dust samples and commercial dog extracts. J Allergy Clin Immunol 1991;88:847-53.

15 Chapman MD, Woodfolk JA, Heyman PW. Cat allergy. Ann Allergy 1992;69:273-5.

16 Ingram JM, Sporik R, Rose G, et al. Quantitative assessment of exposure to $\operatorname{dog}($ Can f 1) and cat (Fel d 1) allergens: relation to sensitization and asthma among school children living in Los Alamos, New Mexico. J Allergy Clin Immunol 1995;96:449-56.

17 Chua K-Y, Stewart GA, Thomas WR, et al. Sequence analysis of cDNA coding for a major house dust mite allergen, Der $\mathrm{p} 1$. Homology with cysteine proteases. J Exp Med 1988;167:175-82.

18 King C, Simpson RJ, Moritz RL, et al. The isolation and characterization of a novel collagenolytic serine protease allergen (Der $\mathrm{p}$ 9) from the dust mite Dermatophagoides pteronyssinus. J Allergy Clin Immunol 1996:98:739-47.

19 Herbert CA, King CM, Ring PC, et al. Augmentation of permeability in the bronchial epithelium by the house dust mite allergen Der $\mathrm{p} 1$. Am J Respir Crit Care Med 1995; 12:369-78.

20 Lemarchand $\mathrm{P}$, Chinet T, Collignon MA, et al. Bronchial clearance of DPTA is increased in acute asthma but not in chronic asthma. Am Rev Respir Dis 1992;145:147-52.

$21 \mathrm{Helm}$ BA. Is there a link between the nature of agents that trigger mast cells and the induction of immunoglobulin (Ig)E synthesis? In: Atassi MZ, ed. Immunobiology of proteins and peptides. VII ed. New York: Plenum Press, 1994:1-10.

22 King C, Brennan S, Thompson PJ, et al. Dust mite proteolytic allergens induce cytokine release from cultured airway epithelium. J Immunol 1998;161:3645-51

23 Boucher RC. Human airway ion transport: Part two. Am J Respir Crit Care Med 1994; 150:581-93.

24 Ichikawa K, Vailes LD, Pomes A, et al. Molecular cloning, expression and modelling of cat allergen cystatin (Fel d 3), a cysteine protease inhibitor. Clin Exp Allergy 2001;31:1279-86.

25 Amin K, Ludviksdottir D, Janson C, et al on behalf of the BHR Group. Inflammation and structural changes in the airways of patients with atopic and nonatopic asthma. Am J Respir Crit Care Med 2000;162:2295-301.

26 Wickens K, Douwes J, Siebers R, et al. Determinants of endotoxin levels in New Zealand homes. Indoor Air 2003;13:128-35.

27 Michel O, Ginanni R, Duchateau J, et al. Domestic endotoxin exposure and clinical severity of asthma. Clin Exp Allergy 1991;21:441-8.

28 Gehring U, Heinrich J, Jacob B, et al. Respiratory symptoms in relation to indoor exposure to mite and cat allergens and endotoxins. Indoor Factors and Genetics (INGA) Study Group. Eur Respir J 2001;18:555-63.

29 Thorn J, Rylander R. Inflammatory response after inhalation of bacterial endotoxin assessed by the induced sputum technique. Thorax 1998;53:1047-52.

30 Vogelzang PF, van der Gulden JW, Folgering $\mathrm{H}$, et al. Longitudinal changes in bronchial responsiveness associated with swine confinement dust exposure. Chest 2000;117:1488-95.

31 Michel O, Ginnani R, Sergysels R. Relation between the bronchial obstructive response to inhaled lipopolysaccharide and bronchial responsiveness to histamine. Thorax 1992;47:288-91.

32 Michel O, Kips J, Duchateau J, et al. Severity of asthma is related to endotoxin in house dust. Am J Respir Crit Care Med 1996;154:1641-6. 